Publisher policy allows this work to be made available in this repository. Published in Economic Policy under Uncertainty: The Role of Truth and Accountability in Policy Advice (ed. by Mooslechner P, Schuberth $\mathrm{H}$, Schuerz M), copyright Edward Elgar Publishing. The original publication is available at: http://www.eelgar.co.uk/Print product detail.lasso?id=3185

The only uses of this work permitted are private study or research. 


\section{The Issue of Uncertainty in Economics}

\section{Sheila C. Dow ${ }^{*}$}

To teach how to live without certainty, and yet without being paralysed by hesitation, is perhaps the chief thing that philosophy, in our age, can still do for those who study it. (Russell 1946, p.14)

\section{INTRODUCTION}

Policy-makers are required to act, even if the action is a continuation of the status quo. The institutional structure within which monetary policy is made requires that a decision is taken at regular intervals as to the repo rate to be set by the central bank. This decision has to be taken on some grounds, and the focus here is on the grounds which economics provides.

It is clear that such decisions are not made under conditions of certainty. The Minutes of the Bank of England Monetary Policy Committee, for example, reveal that the arguments put forward by each member involve more or less uncertainty, but also that the arguments among all the members can be quite diverse. Indeed the Bank of England's inflation forecast is expressed in the form of a 'fan', whose amplitude is a measure of uncertainty surrounding the core forecast.

That this uncertainty should be made so explicit, and so public, is an interesting development in itself, contrasting with such periods as the 1980s when policy-making was made apparently with great confidence on the basis of large macro models. Experience showed that much of this confidence was misplaced.

But if we cannot be certain as to the outcome of policy actions, what is their justification? There is a long tradition of Austrian, or neo-Austrian, economics within which the scope for policy action is limited on the grounds that the knowledge base of policy-makers is insufficient, relative

* Department of Economics, University of Stirling, Stirling FK9 4LA, Scotland UK, s.c.dow@stir.ac.uk, August 2003. Presented to the Economic Methodology Workshop, Oesterreichische Nationalbank, Vienna, 18 October 2002. 
to that of economic actors. Indeed the macroeconomic aggregates on which policy is designed to impinge are seen as having limited meaning.

The purpose of this chapter is to explore the concept of uncertainty and how it affects the foundations of policy-making in economics. We start by considering what we mean by uncertainty, and its source. We will consider first the distinction between uncertainty as a property of the real world, and uncertainty as a property of our knowledge about the real world. We then consider the distinction between uncertainty as a subjective concept and as an objective concept. Economic actors and their knowledge of the real world are the subject matter of economics; in the third section we consider their knowledge and uncertainty in relation to the knowledge and uncertainty of economists about them. We consider how both economists and economic actors can deal with uncertainty, introducing partial, provisional closures in order to construct knowledge about an open system. We conclude by taking further the explicit question of monetary policy-making under uncertainty.

\section{THE NATURE AND SOURCE OF UNCERTAINTY}

The term 'uncertainty' is being used here with a much broader meaning than is often the case in economics. By uncertainty we mean here unquantifiable risk, although quantifiable risk is often referred to in economics as uncertainty. If risk is quantifiable, we can insure against it. It is of limited interest because it allows the focus to continue to be on the core prediction. Of course greater quantifiable risk is relevant to decision-making, when the potential loss arising from outlying outcomes is taken into account. Indeed much of the monetary policy literature dating from Brainard (1967) and Poole (1970) has focused on the significance of higher variance in the error terms of equations representing the transmission of monetary policy. But much of the macroeconomics which provides the foundation for policy advice has effectively ignored the size of error variance; as long as the error term has zero mean and is normally distributed, the stochastic nature of the system can effectively be ignored, and certainty equivalence assumed.

Quantifiable risk has been the main focus of economics, rather than unquantifiable risk, because of the attractions of mathematical formalism (see Backhouse 1998, for a modified advocacy of this position, and Blaug 1999, for a historical account). But the possibility of unquantifiable risk needs to be addressed, not least because its existence is evident. Keynes introduced his Treatise on Probability (where he treated degrees of certainty and degrees of probability as equivalent) as follows: 
In most branches of academic logic . . all arguments aim at demonstrative certainty. They claim to be conclusive. But many other arguments are rational and claim some weight without pretending to be certain. In metaphysics, in science, and in conduct, most of the arguments, upon which we habitually base our rational beliefs, are admitted to be inconclusive in a greater or lesser degree. (Keynes [1921] 1973, p. 3, emphasis in original)

Considering the source and extent of uncertainty gets to the heart of economics and its philosophical foundations.

Uncertainty is a property of knowledge. But a distinction is drawn in the literature regarding the source of uncertainty, that is, between aleatory and epistemic uncertainty (see Lawson 1988, for a full discussion). The former is uncertainty which arises from the nature of the real world, while the latter arises from our capacity to have knowledge about the real world. If there is randomness in nature, for example, so that an economy experiences random real shocks, then our knowledge of these shocks is inevitably incomplete, and therefore our ability to predict is limited accordingly. Randomness however is measurable and entails certain knowledge that shocks are random, so that this representation of aleatory uncertainty in fact corresponds to quantifiable risk. Aleatory uncertainty in the broader sense of unquantifiable risk is much less easy to pin down; we may not have any basis for knowing that the real world conforms to a stochastic system.

Epistemic uncertainty arises from an inability to know the real world. In the monetary policy literature, epistemic uncertainty can arise because of lags in the availability of data, or because of an inability to measure variables such as potential output (see Goodhart 1999). More generally, epistemic uncertainty understood as bounded rationality refers to limitations on the human ability to compute. The presumption is that in principle the economic structure and the mechanism for the transmission of monetary policy are knowable, but in practice we cannot fully access this knowledge. The implication of much of the discussion in the theoretical literature is that it is simply a matter of time before impediments to knowledge are overcome (see for example Blanchard and Fischer 1989, p. 505). The policy literature is less sanguine. This type of epistemic uncertainty is less amenable to capturing in a random error term, so the (policy-focused) model uncertainty literature has addressed this type of uncertainty by considering policy rules which are robust across a range of possible representations of the real world (see for example Bray et al. 1995).

But it may be that the nature of the real world is so complex that we cannot have full knowledge of it, even in principle; this may be one way of understanding the human condition. Indeed David Hume's theory of 
human nature involved this inevitable limitation on knowledge; this was the source of his (commonly misunderstood) problem of induction (Dow 2002). Observation gives us clues to underlying causal mechanisms and we build knowledge as best we can, but we have no direct access to knowledge of these mechanisms.

Further, since human knowledge and action based on this knowledge are central to the real world of social systems, the distinction between aleatory and epistemic uncertainty becomes blurred. To pursue this idea, it is helpful to consider what the uncertainty is about. In most of the monetary policy literature the goal is to construct a model which represents the economic structure and the transmission of monetary policy within that structure. What cannot be pinned down is classified as uncertainty. If the structure the economist is trying to capture is stochastic, uncertainty is aleatory. If there are difficulties in pinning down the structure, uncertainty is epistemic. This classification presumes that the economic system is such that it can be captured in a model. If on the other hand the real world is complex and organic, with behavior and institutions evolving over time, sometimes gradually and sometimes with discrete shifts, then it cannot conceivably be fully captured in a model. Models will capture aspects of that complexity and thus add to knowledge. But that knowledge is inevitably partial and provisional. It is not just that there are limitations to human knowledge. These limitations are inevitable not only because of human failings, but also because of the nature of the real world about which we are trying to build up knowledge, and of which human nature is a central part. The creativity of individuals as well as the evolving social patterns of behavior mean that the economic structure changes in inevitably unpredictable ways.

It is helpful to recall Popper's (1982) three-way classification of the universe: world 1 is the physical world, world 2 the psychological world, and world 3 the product of the human mind. The first two constitute one of the conventional understandings of the subject matter of economics to which the concept of aleatory uncertainty may be applied. World 3 is the province of epistemic uncertainty. But, as Popper argues, the three worlds are all interdependent, with human constructions being both the product of worlds 1 and 2, and in turn affecting them. Popper concluded that, taken together, the three worlds produce an indeterminate whole. The indeterminacy is not stochasticness, but a more profound indeterminacy which means that the universe is an open system. Once we understand the universe as an open system, according to Popper, it cannot be represented by a deterministic (even if stochastic) model. It is therefore no longer appropriate to talk in terms of the 'true' model about which we are uncertain. There is no such thing (other than hypothetically, 
as something known by the deity). Epistemic uncertainty therefore follows from, and in turn contributes to, the openness of the real world.

A more appropriate distinction may then be between subjective uncertainty and objective uncertainty. Subjective uncertainty refers to the individual perceptions of the real world, and the different psychological states of different individuals. This can be distinguished from the degree of uncertainty which it is in some sense rational to hold with respect to a given body of knowledge. This distinction is important for the (neo-) Austrian approach to knowledge. Methodological individualism emphasizes the subjective. But the Austrian approach stems from a particular understanding of the nature of the real world as an open system (a particular ontology). It is therefore logically compatible with a less subjectivist approach which sees objective grounds for uncertainty arising from the openness of the economic system. There is a huge debate in the literature on this subject, not least about how to understand Keynes in relation to subjectivism and objectivism with respect to uncertainty (see for example Davis's 1994 account). But in fact the focus on duals (such as objective/subjective) is itself more compatible with a closedsystem approach. By exploring an open systems approach here, we emphasize more the totality of uncertainty as arising from the openness of the real world, rather than dualistic categories (see further Dow 1990).

In order to function in this real world, individuals do build up knowledge, albeit uncertain knowledge. Indeed, it was central to Menger's (1963) contribution that institutional arrangements evolve in order to provide a reasonably stable foundation for knowledge. So the economic structure itself is conditioned by knowledge limitations and attempts to surmount them. Similarly, the project of science can be understood as an exercise in reducing uncertainty about the real world, and in turn impacts upon the real world. Epistemic uncertainty and efforts to address it become bound up with the real economic structure and thus with sources of aleatory uncertainty. In the next section we focus on the parallelism between the efforts of economic actors to reduce uncertainty and the efforts of economists (see Dow 2003, for a fuller account).

\section{UNCERTAINTY OF ECONOMISTS AND UNCERTAINTY OF ECONOMIC ACTORS}

As a social science, economics is concerned with individual and social action, within social structures. Economists therefore aim to build up knowledge about this action and these structures. This provides the basis for policy action and the design of economic structures. But knowledge in turn can be understood to be central to both action and structures 
within the economy, so that issues of uncertainty can be seen to impact both on the subject matter and on economic science. In the passage quoted above from Keynes's Treatise on Probability, he clearly sees the issues as applying to science and to conduct.

Knowledge has been even more central to the Austrian understanding of the economic process. Drawing on this tradition and the Marshallian tradition, there is a large modern literature which sees knowledge at the core of economic reality. A key contributor to this literature, Brian Loasby, draws explicit parallels between the way in which knowledge is generated in the firm and in markets, and the way in which it is generated among economists (see for example Loasby 1999). He goes back (most recently in Loasby, forthcoming) to Smith in a way which resolves the objectivity/subjectivity dualism which has the potential to threaten a blending of the Austrian and Marshallian traditions. Drawing on Hume, Smith accepted that truth was not demonstrable. He turned therefore from a rational account of science to a psychological account, focusing on the motivation for science and the basis for reasoned persuasion to accept (provisionally) one account of reality over another. Although science was explained in psychological terms, it was not seen as subjective (as the dual of objective) since it was grounded first in a belief in the existence of the real, and second in practice (both scientific and non-scientific). Indeed, the methodological individualism of Austrian economics has accordingly recently been conditioned by its blending with evolutionary economics, such that individual behavior is seen as conditioned by preexisting institutions (see for example Caldwell and Boehm 1992).

Loasby (forthcoming) further explores the role of closed models in building up knowledge of an open reality. For firms, some closure is a necessary feature of knowledge as the basis for action; for example, planning requires some expectation as to the outcome of innovation (some closure in what we might think of as an inherently open process). The firm itself is a form of closure. Action is based, and institutions are designed, on the basis of the identification of patterns, of connections which are understood to be present as opposed to absent. The very notion of a system entails incomplete connectedness of reality. Similarly, as economists, we build theoretical systems on the basis of patterns which we understand to be present in nature.

A fixedly closed system precludes uncertainty (as opposed to quantifiable risk); it requires internal relations to be given, and external forces to be random. In reality a perpetually closed system is generally unsustainable; firms come and go, institutions evolve. Provisional closure is necessary for action, while perpetual attention to change from within and without leads to paralysis. Further, provisional closure itself reduces uncertainty for other actors. The existence of labor contracts, of posted 
product prices, of stable institutions all serve as a set of patterns within which action can be taken. Periods of crisis are those where familiar patterns break down, uncertainty is rife, and paralysis sets in.

Chick and Dow (2001) argue that the methodology of employing partial, provisional closures in order to build up knowledge of an open reality allows for generality. It reflects the generality of uncertainty, while allowing different partial closures to reflect different contexts. Further, this kind of pluralist analysis may simultaneously employ different closures, even when addressing a single context. Thus one part of the analysis may take the money supply as given, while another part explores the process which determines the money supply.

The provisional closures within which actors make decisions in the economy can be thought of as models. They are human constructs which facilitate the economic process. When actors are uncertain they can be thought of as being uncertain about whether there is good reason to continue with the models they provisionally employ as the basis for action. There is apparently a direct parallel with the model uncertainty of economists. The critical issue however is what the uncertainty is about. We need to distinguish between uncertainty as to which is 'the best model' and uncertainty as to which is 'the best collection of provisional, partial models', that is between monism and pluralism.

The model uncertainty literature in general avoids this parallelism between economists' knowledge and the knowledge of economic actors. The literature which assesses the relative merits of a given range of leading macroeconomic models makes no comment on the fact that these models depict individual economic actors as displaying no such uncertainty. Similarly, the Bank of England (1999), which in other respects is most outspoken on the need for pluralism as the basis for policy decisions, nevertheless employs models which presume certainty equivalence among economic actors. The major exception is work in which Sargent plays a leading part, such as Sargent (1999); he is concerned with symmetry of treatment between economist and agent. But to make agents' uncertainty and the uncertainty of economists tractable, it is depicted for both as a complex stochastic process which is subject to pre-defined limits. What is expressed as uncertainty is in fact risk with respect to knowledge of the true model of the economic structure.

Keynes (1921) explicitly addressed the question of how individuals (in the economy, or economists, or whatever) establish reasoned grounds for belief such as to provide a basis for action; this found an echo later (Keynes 1937) when he encapsulated a key element of the General Theory, the theory of liquidity preference. In the absence of a true model which individuals or economists could aim to access, given the openness of the real world, no one best route to knowledge can be identified. 
Action, according to Keynes, is based on reason (understood as rational grounds for belief), subject to a psychological force (intuition, animal spirits, and so on). Classical logic alone is insufficient to justify action since we cannot be certain of the outcome of our actions, far less the environment within which they will be played out. For Keynes, reason is instead based on ordinary logic, or human logic, which does not require certainty as to the truth or falsity of premises.

Ordinary logic, for economic actors and for economists, consists of multiple strands of reasoning, drawing on a range of sources of direct knowledge. Both actors and economists employ a pluralist methodology. Recourse is made to convention. In the absence of adequate knowledge derived from individualistic rationality, conventional knowledge is built up at a societal level. When forming expectations under uncertainty, individuals use what individual knowledge they have, but also refer to expert sources and indicators of societal expectations. The framework within which knowledge is formed and action taken is a set of conventions and institutions built up over the years in response to the need to cope with uncertainty, ranging from the rule of law to conventional market behavior. But by the same token expectations, lacking a rationalistic foundation, are subject to periodic discrete shifts. A change in conventional understanding, due for example to a highly publicized event, or an expression of a new expectation by a leading pundit, can have widespread consequences for expectations, for the degree of uncertainty with which they are generally held, and for ensuing action.

The same is true of economists. One of the major insights of Kuhn's (1962) approach, taken forward by the sociology of scientific knowledge, or science studies, is that scientific communities' normal research is built on a conventional foundation shared by the members of the community. The modern rhetoric approach, echoing Smith's theory of rhetoric, focuses on what is conventionally persuasive in the presentation of new ideas. Further, these conventions are embedded in an institutional structure set up to provide a basis for scientific activity: journals, textbooks, conferences, and so on. Were scientific knowledge not subject to uncertainty then rationalistic arguments could compete in a world akin to perfect competition. But, just as that world is impractical for markets in general in a world of uncertainty - markets require conventional behavior and institutions in order to function - so too scientific communities require some underpinning. This introduces some closure which allows science to proceed. But there is an inevitable circularity in the conceptual framework conventionally adopted by a particular community or paradigm, the way it understands the economic system, and the way it understands arguments about that system (see Loasby 
2002). A fixed closure is unsustainable and science is subject to paradigm shifts just as conventional expectations are subject to discrete shifts. Economic paradigms do evolve over time, responding to experience of reality which challenges a particular choice of closure.

Monetary policy provides an excellent example of such a challenge. We turn in the next section to consider where this discussion takes us in considering the methodological foundations for monetary policy.

\section{UNCERTAINTY AND MONETARY POLICY}

The conventional closure involved in basing policy on one large macro model, treated as the 'true' model, was confronted by the experience of predictive failure (see for example Clements and Hendry 1995). One response has been the Bank of England's (1999) professed embracing of pluralism (although there is still an emphasis on one core macro model).

The 1980s can be understood as a period in which policy was based on a form of humanism. There was optimism that the large macro models provided an adequate guide to policy action, which could be expected to yield the predicted outcomes. This optimism was gradually punctured when these expectations were confounded. The prevailing paradigm of New Classical Economics had relied on certainty equivalence on the part of economic actors and economists alike. Within this paradigm, there emerged the Lucas critique which challenged one of the closures within the model structure: that behavior was invariant in the face of policy action. Lucas (1976) argued that rational individuals in fact respond to policy action in such a way as to make it impotent. The conclusion was that policy action could only have an impact on the economy if it was random, that is there was no point in policy action.

This conclusion found support from a line of argument which took a very different starting-point. Far from individuals and economists knowing too much, the problem with policy action might derive from unknowability resulting from radical uncertainty. Thus Hayek, for example, expressed the radical uncertainty of the Austrian approach as grounds for an argument against humanism:

If man is not to do more harm than good in his efforts to improve the social order, he will have to learn that . . . where essential complexity of an organised kind prevails, he cannot acquire the full knowledge which would make mastery of the events possible. He will therefore have to use what knowledge he can achieve, not to shape the results as a craftsman shapes his handiwork, but rather to cultivate a growth by providing the appropriate environment, as the gardener does for his plants. (Hayek 1975, p. 42, emphasis in original) 
This argument attracted support from a wide range of perspectives which were influenced by the emergence of postmodernism, which more generally challenged humanism. Thus for example, while starting from a closed-system theoretical perspective based on certainty-equivalence like Lucas, Hahn (1983) denied the empirical validity of the New Classical approach - the knowledge requirements could not in practice be met. Like those coming from a radical uncertainty perspective, Hahn therefore raised questions as to how policy intervention could be justified.

The Keynes uncertainty approach is aimed more at a middle ground (an argument developed in detail by O'Donnell 1989). Uncertainty itself justifies government intervention, since it can serve to provide an element of stability for economic actors. O'Donnell explains this role in terms of knowledge and institutions:

State activity was thus a precondition of successful individualism, improving the efficiency of resource utilisation and eliminating some of the hazards of pure laissez-faire. By attacking remediable sources of uncertainty, providing data banks and by reforming institutions, it could improve the environment in which individual rationality was exercised. (O'Donnell 1989, p. 303, emphasis in original)

The role is extended by the content of Keynesian fiscal and monetary policy - both are designed to provide a sound basis for investment; in the case of fiscal policy the government may actively intervene by engaging in its own capital projects to increase aggregate demand.

The implementation of this policy arguably was so successful that the relative stability of the 1950s and 1960s encouraged inattention to issues of uncertainty and expectations. The neo-classical synthesis of that period ignored these central features of Keynes's economic theory. This coincided with a high level of confidence in the capacity of the state to manage the economy and a continuation of closures in theorizing which became increasingly untenable, leading to the New Classical revolution.

There has been a dualistic swing away from humanism, but now a return to seek out some middle ground. Central banks, including the $\mathrm{ECB}$, are addressing methodological issues as they grapple with the uncertainty of their knowledge in the face of the requirement to act. This is a time of rather uncomfortable transition, as old closures (such as certainty-equivalence on the part of economic agents) bump up against the actual uncertainty of policy-makers. The Bank of England has taken a lead by pointing to pluralism as the methodological route to follow. But much needs to be done to spell out what that entails for how the knowledge foundations of monetary policy are constructed. 


\section{CONCLUSION}

We have addressed here the fundamental issues raised for economics by a consideration of uncertainty in its broadest sense. These issues get to the heart of what it is that we do as economists, as well as what we do as economic actors. There is a danger of falling into one or the other of two sharp categories with respect to knowledge: the certainty equivalence of closed-system models on the one hand and the radical uncertainty of completely open systems on the other. Both inhibit policy action. But by considering the middle ground where some closures are introduced (by individuals, by social institutions, by government, by theorists) in order to reduce uncertainty, we can see how social structures do manage to function in spite of uncertainty, and how actions to affect behavior and institutional design may serve to reduce uncertainty.

The methodological approach implied by this middle-ground is a form of pluralism - not 'anything goes', but a recourse to a range of methods and types of knowledge suited to the problem at hand and the type of economic structure within which it is understood to occur. This seems to be what central bankers tend to do anyway, being closer to the real world and more compelled to action than academic economists. But there is still an uncomfortable juxtaposition between this practice and the approach which is often professed by central bankers as well as academics: modeling which is closed-system in a fixed way, rather than in the partial, provisional way of the pluralist approach. A fundamental rethink at the methodological level is required to produce an approach to the knowledge base of policy which is philosophically consistent in a world profoundly colored by uncertainty.

\section{REFERENCES}

Backhouse, R.E. (1998), 'If mathematics is informal, then perhaps we should accept that economics must be informal too', Economic Journal, 108 (451), $1848-58$.

Bank of England (1999), Economic Models at the Bank of England, London: Bank of England.

Blanchard, O. and S. Fischer (1989), Lectures in Macroeconomics, Cambridge, MA: MIT Press.

Blaug, M. (1999), 'The Formalist Revolution or What Happened to Orthodox Economics after World War II?', in R.E. Backhouse and J. Creedy (eds), From Classical Economics to the Theory of the Firm: Essays in Honour of D.P. O'Brien, Cheltenham, UK and Northampton, MA, USA: Edward Elgar, pp. 257-80. 
Brainard, W. (1967), 'Uncertainty and the effectiveness of policy', American Economic Review Papers and Proceedings, 57, 411-25.

Bray, J. et al. (1995), 'The interfaces between policy-makers, markets and modellers', Economic Journal, 105 (431), 989-1000.

Caldwell, B.J. and S. Boehm (eds) (1992), Austrian Economics: Tensions and New Directions, Boston: Kluwer.

Chick, V. and S.C. Dow, (2001), 'Formalism, logic and reality: a Keynesian analysis', Cambridge Journal of Economics, 25 (6), 705-22.

Clements, M.P. and D. Hendry, (1995), 'Macroeconomic forecasting and modelling', Economic Journal, 105 (431), 1001-31.

Davis, J.B. (1994), Keynes's Philosophical Development, Cambridge: Cambridge University Press.

Dow, S.C. (1990), 'Beyond dualism', Cambridge Journal of Economics, 14 (2), 143-58.

Dow, S.C. (2001), Uncertainty and Monetary Policy, University of Stirling mimeo.

Dow, S.C. (2002), Economic Methodology: An Inquiry, Oxford: Oxford University Press.

Dow, S.C. (2003), 'Probability, Uncertainty and Convention: Economists' Knowledge and the Knowledge of Economic Actors', in S. Mizuhara and J. Runde (eds), Perspectives on the Philosophy of Keynes's Economics: Probability, Uncertainty and Convention, London: Routledge.

Goodhart, C.A.E. (1999), 'Central bankers and uncertainty', Bank of England Quarterly Bulletin, February, 102-16.

Hahn, F.H. (1983), Money and Inflation, Cambridge, MA: MIT Press.

Keynes, J.M. (1921), A Treatise on Probability, reprinted in (1973), Collected Writings, Vol. VIII, London: Macmillan for the Royal Economic Society.

Keynes, J.M. (1936), The General Theory of Employment, Interest and Money, reprinted in (1973), Collected Writings, Vol. VII, London: Macmillan.

Keynes, J.M. (1937), 'The general theory of employment', Quarterly Journal of Economics, 51, 209-23.

Kuhn, T.S. (1962), The Structure of Scientific Revolutions, Chicago: University of Chicago Press.

Lawson, T. (1988), 'Probability and uncertainty in economic analysis', Journal of Post Keynesian Economics, 11 (1), 38-65.

Loasby, B.J. (1999), Knowledge, Institutions and Evolution in Economics: the Graz Schumpeter Lectures, London: Routledge.

Loasby, B.J. (2002), 'Closed models and open systems', Journal of Economic Methodology.

Lucas, R.E. Jr. (1976), 'Econometric Policy Evaluation: A Critique', in K. Brunner and A.H. Meltzer (eds), The Phillips Curve and Labor Markets, North-Holland, Amsterdam, and Carnegie-Rochester Conference Series on Public Policy, Vol. 1, a supplementary series to the Journal of Monetary Economics.

Menger, C. (1963), Problems of Economics and Sociology, Urbana, ILL: University of Illinois Press.

O’Donnell, R.M. (1989), Keynes: Philosophy, Economics and Politics: The Philosophical Foundations of Keynes's Thought and their Influence on his Economics and Politics, London: Macmillan. 
Poole, W. (1970), 'Optimal choice of monetary policy instruments in a simple stochastic macro model', Quarterly Journal of Economics, 84 (May), 197216.

Popper, K. (1982), The Open Universe: An Argument for Indeterminism, London: Routledge.

Russell, B. (1946), History of Western Philosophy, London: George Allen and Unwin.

Sargent, T.J. (1999), 'Comment', in J. Taylor (ed.), Monetary Policy Rules, Chicago: University of Chicago Press, pp. 144-54. 
